\title{
Antecedents to Trustworthiness, Satisfaction, and Potency in ad hoc Face-to-Face and Computer-Mediated Teams
}

\author{
Paul H. Jacques \\ Rhode Island College \\ John Garger \\ The Science Survival Academy \\ Leslie P. Filippelli-DiManna \\ American International College
}

\begin{abstract}
Author Note
Paul H. Jacques, Management and Marketing Department, Rhode Island College; John Garger, The Science Survival Academy; Leslie P. Filippelli-DiManna, School of Business Arts $\&$ Sciences, American International College.

A previous version of this paper was presented at the Eastern Academy of Management 2018 Annual Meeting.

Correspondence concerning this article should be addressed to Paul H. Jacques, Management and Marketing Department, Rhode Island College, 600 Mount Pleasant Avenue, Providence, RI 02908.

E-mail: pjacques@ ric.edu
\end{abstract}




\begin{abstract}
This paper tests a model that links individual perceptions of mood, trust, satisfaction, and potency in face-to-face and computer-mediated teams. Results suggest that the model is valid in both conditions but that perceptions of each construct are higher in face-to-face conditions. A direct connection exists between mood and how benevolence, integrity, and ability are perceived only in the computer-mediated condition. Implications to research include an understanding that in both computer-mediated and face-to-face teams, trust operates similarly, though perceptions are lower when communication media are leaner. When using computer-mediated communication, students might benefit from face-to-face interactions before interacting online.
\end{abstract}

Keywords: computer-mediated teams, trustworthiness, satisfaction, potency, mood

\title{
Antecedents to Trustworthiness, Satisfaction, and Potency in ad hoc Face-to-Face and Computer-Mediated Teams
}

Work teams play a fundamental role in the accomplishment of an organization's goals, and now more than ever, with the Coronavirus outbreak, both professionals and academicians have been removed from their offices, classrooms, and laboratories and placed in a work environment that is nearly exclusively virtual (Gardner \& Matviak, 2020). Herbst (2020) argues that remote work practices have suddenly become a mandate that have forced organizations of all types to adapt to a novel work and learning environment that, in turn, enables a critical mass of individuals and decision-makers to understand the many advantages that virtual environments offer. Only $7 \%$ of U.S. civilian workers engaged in teleworking before the outbreak (Desilver \& Pew Research Center, 2020).

Likoebe and Agarwal (2004) identify advantages of virtual teams, such as increased global presence and the ability of such teams to span a variety of areas-functional, organizational, temporal, and geographic — using computer-mediated media. Organizations are thus able to access knowledge on many levels. Teams are groups that share common objectives and work to achieve those objectives, offering many advantages, such as better solutions, productivity, and creativity. We assess whether constructs operate similarly between two conditions - face-to-face (FtF) and computer-mediated teams (CMTs) — in an ad hoc context. Although this topic applies to businesses, we focus on student teams in an education context. Since professors commonly use ad hoc teams pedagogically, knowing that trust, potency, and satisfaction do not operate the same across the two types of teams explains why teams excel, fail, or require more time to allow these constructs to develop among members.

High-functioning teams share a common characteristic of trust among members. Fuller, Marett, and Twitchell (2012) argue that team development relies on trust and mutuality. Jarvenpaa, Knoll, and Leidner (1998) focus on the benefits of trust in a team, which translates to reduced transaction costs, more confidence and security among members, and open exchanges that contribute to a team's objectives. Self-perception of skills correlates with perceptions of competency and ability, and as group members interact, care and concern for one another develop. Expressing empathy and considering what is best for the group as a whole versus egocentric motives represent benevolence, and integrity influences trust in a group. Dependability, reliability, and the ability to adhere to positive and productive work habits 
increases trust among members. In CMT, the absence of direct interactions and thus a context in which behaviors occur represent barriers to a team's functioning (Jarvenpaa et al., 1998).

Trust is particularly important in CMTs due to perceptions of uncertainty and risk (Breuer, Huffmeier, \& Hertel, 2016); disparities between trust, in which a member of a group is willing to be vulnerable, and risk-taking, a behavior that results when trust is present, are common in such teams. In CMTs, additional uncertainty means less concrete information and less social control in comparison to $\mathrm{FtF}$ teams (Breuer et al., 2016). Relationships alter the nature of exchanges, which, in turn, alter relationships (Cropanzano \& Mitchell, 2005). Instructors especially find this information useful when assisting students who are operating in CMTs. Social exchange theory, which explains relationships and expectations that develop during exchanges between two or more people, and attribution theory, which explains how people attribute causes to events and behaviors, apply in CMTs. Connelly and Turel (2016) found that most individuals perceive that they are capable of accessing others' emotional authenticity by focusing on the content and tone of online messages. Using affect theory of social exchanges, Lawler (2001) argues that people analyze their emotions and feelings produced when interacting successfully and unsuccessfully to create a sense of order and harmony regarding relationships, whether at the individual, group, or network levels. Barsade (2015) found that group affect shapes group activities and outcomes, and Chesin, Rafaeli, and Bos (2011) argue that people watch the behaviors of others to identify the emotions felt, reacting to such moods and behaviors as a result. Lawler (2001) also examines how individuals avoid negative emotions, instead reproducing positive emotions in response to social exchanges. When FtF with others, individuals act positively knowing that positivity will be received better and is more acceptable than negativity. In a computer-mediated context, this is less likely to happen. Tseng and $\mathrm{Ku}$ (2011) suggest that trust improves among interactions and positive experiences, but the opposite is true since trust deteriorates quickly when communication is unclear, behaviors contradict expectations, and negative intentions are perceived. Lawler (2001) addresses whether emotion management hides emotions and whether individuals manage them to maintain positive social exchanges. We assess whether trust drives team success and the effect mood has on trust among team members. We argue that in CMTs, mood affects team members more than those who engage $\mathrm{FtF}$, and thus we assess the effect of mood on the functioning and productivity of teams.

\section{Literature Review}

\section{Aspects of Trust}

Three characteristics comprise trust — ability, benevolence, and integrity — with Mayer and Davis (1995) noting the parallel with Aristotle's Rhetoric (1877), in which ethos is described as being based on one's intelligence, character, and goodwill. Ability, benevolence, and integrity influence trust, varying independently across individuals (Kuo \& Thompson, 2014; Mayer \& Davis, 1995). Mayer and Davis (1995) argue that trustworthiness and the antecedents of trust vary along a continuum and are affected by context. Jarvenpaa et al. (1998) found that trust is essential when self-direction and self-control are required, such as in the absence of supervision in CMTs. Lower transaction costs, increased relational certainty, and more effective communication are outcomes of trust (Jarvenpaa et al., 1998). Tseng and $\mathrm{Ku}$ (2011) describe 
trust as a bond that keeps a team together and encourages interdependence among team members, resulting in productive teamwork.

In a FtF context, time is needed for trust to develop, but in CMTs, context represents a barrier to developing relationships and thus the trust required for productive exchanges. Jarvenpaa et al. (1998) found that high-trust team members are more focused, engage in better communication, and are more supportive of one another in comparison to members in low-trust teams. Lowry, Schuetzler, Giboney, and Gregory (2015) found that in $\mathrm{FtF}$ groups, trust can be detrimental and distrust instrumental to a group's decision-making; groups constructed more optimal solutions when faced with non-routine, unfamiliar problems, which carried over to virtual teams that outperformed other types of groups.

\section{Mood, Emotions, and Feelings}

Given the importance of trust in teams, both $\mathrm{FtF}$ and computer-mediated, the question of what effect mood has on trust between team members is salient. Chesin et al. (2011) argue that emotions carry social influence and play a social role; people commonly show emotions when they experience them (Fowler \& Christakis, 2008). Emotion contagion is "an unconscious process attributed to mimicking of non-verbal cues" (Chesin et al., 2011, p. 2). Moods and emotions are distinct, with moods typically lasting longer and being less intense than emotions, and not deriving from a specific cause. However, in teams, moods and emotions blur. Emotion contagion affects a team when one member's emotions spread and unconsciously shape others' moods. Non-verbal cues are the primary means by which emotion contagion spreads, but in CMTs, cues are limited. Negative emotions give way to shorter messages, more negative terms, and slower responses over text-based messaging (Chesin et al., 2011). Anticipatory contagion occurs when individuals match the mood of someone with whom they have not previously had contact but with whom they were about to interact. People in a positive frame of mind are more flexible and therefore happy, and a positive mood offers social cues that there is psychological safety or interpersonal security when interacting with such individuals (Liu et al., 2015).

Totterdell, Kellett, Teuchmann, and Briner (1998) found that people are affected by the moods of those around them. Barsade and Gibson (2000) use the term interaction synchrony to represent "the tendency for group members to automatically adjust their behavior to synchronize with other members' behavior" (p. 119), which is particularly true if a relationship involves people who are close and have known one another for some time. Mood reciprocation results in a sense of shared similarity in a work team; when an individual's mood is positive, the resulting team's mood is similarly positive, and if the mood is negative, team members share that negativity. Totterdell et al. (1998) identify primitive emotional contagion as the result of a nonconscious process that results in mood induction; people are affected by the moods of others in a group. Kramer, Guillory, and Hancock (2014), however, argue that contagion results not from exposure to an emotion, but the interaction experienced, even if only textual. Volmer (2012) discusses affective events theory, which suggests that both positive and negative occurrences at work affect employees' feelings, attitudes, and performance. Over time, mood exchanges result in mood links, depending on the relationship, and thus more research is needed to examine moods and their effects on CMTs. 
Online disinhibition effect (Lapidot-Lefler \& Barak, 2012) is a lessening of behavioral inhibitions in online contexts, and the negative variety is the result of individuals using aggressive behaviors that would not normally be engaged in $\mathrm{FtF}$. Knowing that expressions of frustration and anger are socially inappropriate, people hold back such emotions FtF but share them using linguistic cues online (Guillory et al., 2011). Online flaming and other behaviors that damage self-image or someone else's without personal progression are called toxic disinhibition. Flaming means using hostile expressions (e.g., textual elements and hostile language), a mix of letters, numbers, and punctuation that indicates shouting or derogatory names, and even using red or bold fonts to show anger and aggression. Three factors play a role in online disinhibition - anonymity, invisibility, and lack of eye contact (Lapidot-Lefler \& Barak, 2012).

Anonymity is not just being nameless but being unidentifiable in terms of characteristics, such as appearance and personal data. Online anonymity includes invisibility, lack of eye contact, and non-disclosure of personal data. Lapidot-Lefler and Barak (2012) argue that invisibility means no pictures, video, or social presence online with which a person could be recognized, which facilitates control of impression management. Visual anonymity gives a sense of freedom to show feelings clearly, whether antagonistic or friendly. Eye contact is paramount to interpersonal communication, but behaviors that generate negative online disinhibition are induced by lack of eye contact. Even with use of devices that allow visibility (e.g., webcam), insufficient information is transmitted in comparison to direct eye contact, which partially controls interpersonal communication and social regulation, and without it, disinhibition is the result. Disinhibition affects discussion styles, ways of seeking information, learning online, relationships, and group behaviors (Lapidot-Lefler \& Barak, 2012), especially considering the effect mood has on CMTs.

\section{Effect of Mood}

Research suggests that mood has a contagion effect, found among team members and between team members and a leader; when a leader expresses a positive mood, team performance increases (Chi, Chung, \& Tsai, 2011). Liu et al. (2015) explore how the interpersonal role of moods affects an employee's voice or ability to express opinions and ideas about work-related issues. Mood acts as a social cue that conveys attitudes and behaviors to others. From the affect-as-social-information perspective, a positive mood conveys interpersonal security by team members, which creates a safe social context in which team members can use their promotive voices, meaning they feel and speak as if they will be heard and recognized (Liu et al., 2015). The chances of interactions being misinterpreted as personal criticisms thus decrease and receptiveness to challenges increases due to perceived psychological safety that resulted from the expression of a positive mood.

Pfaff (2009, 2012) and Pfaff and McNeese (2010) examine the role mood plays on a team's reasoning, a topic they argue is understudied but that plays a much larger role than previously acknowledged. Stress and emotion influence teams' cognitive task performance (Pfaff, 2009); negative affect or mood decreases a team's outlook to the point of becoming unmotivating. A positive team results in increased team awareness, increased productive communication, and more detailed verbal responses among members. When distinguishing stress 
from mood, opportunities arise to create interventions that support team awareness and enrich task functioning. Thus:

H1: Negative affect correlates negatively with individual perceptions of (H1a) team benevolence, $(\mathrm{H} 1 \mathrm{~b})$ team integrity, and (H1c) team ability in computer-mediated teams.

Positive mood builds trust, and increased trust encourages team members to express opinions, ideas, and feelings with one another and expect reciprocation through acceptance, support, and corresponding disclosures (Tseng \& Ku, 2011). Tseng and $\mathrm{Ku}(2011)$ argue that a high degree of trust results in strong team performance, team satisfaction, and teamwork. Although a negative communicator in a group can have negative repercussions to team performance, Yilmaz (2016) found that negative communication behaviors also trigger higher group performance by pushing others to consider alternatives and think more critically, thereby avoiding hasty decisions that could prove less effective. A dissenting member causes other members to pause and consider what is being said critically, leading to better analysis and adherence to task requirements. Therefore:

$\mathrm{H} 2$ : Individual perceptions of $(\mathrm{H} 2 \mathrm{a})$ team benevolence, $(\mathrm{H} 2 \mathrm{~b})$ team integrity, and

$(\mathrm{H} 2 \mathrm{c})$ team ability correlate positively with team trustworthiness in both face-to-face and computer-mediated teams.

H3: Individual perceptions of team trustworthiness correlate positively with team potency in both face-to-face and computer-mediated teams.

\section{Team and Job Satisfaction}

The purpose of creating a team to work on tasks is to leverage the unique, individual skills and motives that constitute the team; the entity a team represents is an interdependent cluster of individuals. Team trust facilitates the efficiency of exchanging information necessary to team functioning, but more importantly has a direct effect on team performance (Chua, Ingram, \& Morris, 2008; Hempel, Zhang, \& Tjosvold, 2009). Robert and You (2018) found a positive link between trust and satisfaction among team members on virtual teams. In a metaanalysis that assesses antecedents and outcomes of trust in work teams, Costa, Fulmer, and Anderson (2018) found that outcomes of trust include team efficacy and team performance. Therefore:

H4. Individual perceptions of team trust correlate positively with team satisfaction in both face-to-face and computer-mediated teams.

Jung and Sosik (2003) examine group efficacy, also called potency, which becomes increasingly homogenous the more a group interacts. Similar to self-efficacy, a psychological state wherein an individual believes in his/her ability to accomplish goals, group efficacy extends the concept to groups. Groups that perceive greater potency are more effective when completing tasks (Jung \& Sosik, 2003). Furst, Reeves, Rosen, and Blackburn (2004) found that enhanced satisfaction with a focal individual's team relates to increased ratings of team efficacy. Breuer et 
al. (2016) argue that trust relates to team satisfaction and team consistency, with effectiveness found stronger in CMTs. Thus:

H5: Individual perceptions of team satisfaction correlate positively with perceptions of team potency in both face-to-face and computer-mediated teams.

\section{Face-to-Face and Computer-Mediated Teams}

Haines (2014) found that CMTs are able to overcome obstacles and have the same experiences as $\mathrm{FtF}$ teams. Due to the communication used in CMTs, there is greater pressure to conform and accomplish tasks that rely on trust, but as the team develops, greater trust among peers develops and the team works more effectively. Paul and McDaniel (2004) argue that FtF contact is imperative to building trust, but Haines (2004) and Piccoli and Ives (2003) argue that although CMTs experience challenges related to communication and time, they are able to develop high degrees of trust, which must be maintained until a project is complete. A psychological contract, which arises from agreement concerning expectations and obligations, is created among team members as a natural process of reciprocal responsibilities (Piccoli \& Ives, 2003). When that contract was breached, trust was damaged. In CMTs, breaching the psychological contract early on in a group process went largely undetected and had no negative consequences for the team. Potter and Balthazard (2002) similarly found that interaction styles in CMTs that affect performance and processes are similar to those found on conventional teams. Ruiller, Van Der Heijden, Chedotel, and Dumas (2019) suggest that challenges found in a virtual environment differ in comparison to face-to-face contexts, and such differences influence individuals' construction of attitudes toward the team and result from synchronous communication and limited information richness, which in turn might result in misunderstandings/misinterpretations Therefore:

H6: Individual perceptions of team benevolence, team integrity, team ability, team trust, team satisfaction, and team potency are greater in face-to-face versus computer-mediated teams. 


\section{Methods}

The theoretical model tested in this study appears in Figure 1. The model suggests that negative affect correlates with three components of trust-benevolence, integrity, and ability (H1). These three components correlate with perceptions of trustworthiness (H2), which, in turn, predicts potency (H3) and satisfaction (H4). Finally, satisfaction correlates with potency (H5). H6, not represented in Figure 1, suggests that perceptions of benevolence, integrity, ability, trustworthiness, satisfaction, and potency are greater in FtF versus CMTs.

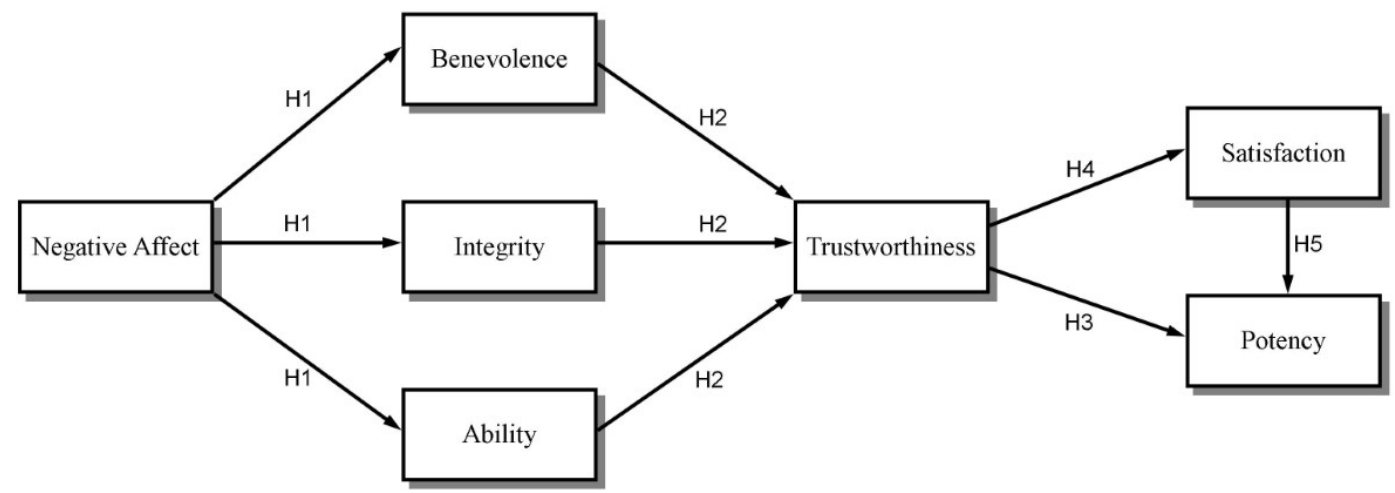

Figure 1. A model of mood, trust, satisfaction, and potency in ad hoc face-to-face and computermediated teams.

\section{Participants}

Participants were 216 students enrolled in 15 sections of 7 management courses at a comprehensive, regional, public university. One hundred participants were female and 115 were male (one participant failed to identify his/her sex). One hundred nine participants were assigned to a CMT condition and the remaining one hundred seven were assigned to a FtF condition. In the CMT condition, 51 participants were female and 58 male, and in the FtF condition, 49 participants were female and 57 male.

\section{Measures}

Negative affect (10 items) was measured using a scale from Watson, Clark, and Tellegen (1988). Benevolence (5 items), integrity (6 items), ability (6 items), and trustworthiness (8 items) were taken from Jarvenpaa et al. (1998). The benevolence, integrity, and ability items were originally from a Schoorman, Mayer, and Davis (2016) working paper, modified by Jarvenpaa et al. (1998) to reflect a team rather than dyadic context. Trustworthiness items were originally from Pearce, Sommer, Morris, and Frideger (1992), also modified by Jarvenpaa et al. (1998) to reflect a team rather than organizational context. A satisfaction measure (13 items) from Keyton (1991) was used to capture a range of global team satisfiers. Potency (8 items) was captured using items from Guzzo, Yost, Campbell, and Shea (1993). Participants rated all items on a Likert-type scale that ranged from strongly disagree (1) to strongly agree (5). Since multiple items were collected for each variable in the model, scale scores were created by calculating a mean of the items for estimation of each construct. 


\section{Procedures}

Participants were assigned randomly to either a FtF team (107 participants) or a CMT (109 participants). Within each condition, participants were assigned randomly into 4-person groups. Groups in both conditions worked together for 30 minutes to complete a brief project that required delivery of a set of solutions on which all members of each group agreed. Since participants included students from multiple courses, a project similar in complexity and difficulty was given to each group in their respective courses. Participants completed a survey to capture the negative affect construct, collected before the participants began the group assignment and before they knew that they would shortly be assigned into either a FtF team or CMT. This was done so that negative affect ratings would not be influenced by the condition to which the participants were assigned. Groups in the FtF condition completed the assignment collocated with one another, but groups in the CMT condition completed the assignment using an online chat program. The program allowed only typed messages to be sent to all members of the group. In the CMT condition, the first and only contact team members experienced was over the chat program to preserve anonymity. Data were analyzed using multiple regression to test $\mathrm{H} 1$ through H5. Standardized betas, F-statistics, and p-values were calculated using computer statistics software. Error terms and multiple square correlations were calculated for the endogenous variables. To assess H6, data were analyzed using an ANOVA to calculate an Fstatistic and p-value.

\section{Results}

Means, standard deviations, scale correlations, and reliabilities for the measures appear in the Table. Figures 2 and 3 summarize results for both the FtF and CMT conditions. Beta values are given as standardized betas.

Negative affect correlated negatively with benevolence (beta $=-0.20, \mathrm{p}<0.01)$, integrity (beta $=-0.25, \mathrm{p}<0.01$ ), and ability (beta $=-0.21, \mathrm{p}<0.05)$ in the CMT condition, supporting H1. Integrity (beta $=0.48, \mathrm{p}<0.01)$ and ability (beta $=0.50, \mathrm{p}<0.01)$ correlated positively with trustworthiness in the FtF condition, partially supporting $\mathrm{H} 2$. Integrity (beta $=0.35, \mathrm{p}<0.01$ ) and ability (beta $=0.58, \mathrm{p}<0.01$ ) correlated positively with trustworthiness in the CMT condition, partially supporting $\mathrm{H} 2$. Benevolence did not correlate with trustworthiness in either the FtF or CMT team condition. In support $\mathrm{H} 3$, trustworthiness correlated positively with potency in both $\mathrm{FtF}$ (beta=0.50, $\mathrm{p}<0.01$ ) and CMT (beta=0.56, $\mathrm{p}<0.01$ ) condition. In support of H4, trustworthiness correlated positively with satisfaction in both the $\mathrm{FtF}$ (beta=0.66, p<0.01) and CMT (beta $=0.75, \mathrm{p}<0.01$ ) condition. Satisfaction correlated positively with potency in both the $\mathrm{FtF}$ (beta=0.44, $\mathrm{p}<0.01$ ) and CMT (beta=0.29, $\mathrm{p}<0.01$ ) condition, supporting H5. An ANOVA suggested that benevolence $(\mathrm{F}=30.01, \mathrm{p}<0.01)$, integrity $(\mathrm{F}=25.44, \mathrm{p}<0.01)$, ability $(\mathrm{F}=27.93$, $\mathrm{p}<0.01)$, trustworthiness $(\mathrm{F}=39.83, \mathrm{p}<0.01)$, satisfaction $(\mathrm{F}=22.34, \mathrm{p}<0.01)$, and potency $(\mathrm{F}=36.52, \mathrm{p}<0.01)$ were higher in the FtF than in the CMT condition, supporting H6. 
FACE-TO-FACE AND COMPUTER-MEDIATED TEAMS

\section{Table}

Means, Standard Deviations, Correlations, and Reliabilities

\begin{tabular}{|c|c|c|c|c|c|c|c|c|c|c|c|}
\hline & \multicolumn{2}{|c|}{ Means } & \multicolumn{2}{|c|}{ SDs } & \multicolumn{7}{|c|}{ Correlations and Reliabilities } \\
\hline & $\mathrm{FtF}$ & $\mathrm{CM}$ & & $\mathrm{CM}$ & & & & & & & \\
\hline & $\mathrm{T}$ & $\mathrm{T}$ & $\mathrm{FtF}$ & $\mathrm{T}$ & 1 & 2 & 3 & 4 & 5 & 6 & 7 \\
\hline 1. Negative & & & 0.7 & & & & & & & & \\
\hline Affect & 1.77 & 1.73 & $\begin{array}{c}6 \\
0.7\end{array}$ & 0.70 & 0.87 & & & & & & \\
\hline 2. Benevolence & 3.84 & 3.33 & $\begin{array}{c}0 \\
0.6\end{array}$ & 0.84 & -0.09 & 0.84 & & & & & \\
\hline 3. Integrity & 3.80 & 3.35 & $\begin{array}{c}4 \\
0.5\end{array}$ & 0.68 & $-0.18^{*}$ & $0.78 *$ & 0.82 & & & & \\
\hline $\begin{array}{l}\text { 4. Ability } \\
\text { 5.Trustworthine }\end{array}$ & 3.90 & 3.44 & $\begin{array}{c}8 \\
0.5\end{array}$ & 0.71 & -0.13 & $0.69 *$ & $0.81 *$ & 0.89 & & & \\
\hline Ss & 4.03 & 3.52 & $\begin{array}{c}7 \\
0.4\end{array}$ & 0.62 & -0.10 & $0.66^{*}$ & $0.78^{*}$ & $0.80^{*}$ & 0.88 & & \\
\hline 6. Satisfaction & 3.68 & 3.37 & $\begin{array}{c}1 \\
0.5\end{array}$ & 0.53 & -0.13 & $0.68 *$ & $0.75^{*}$ & $0.76^{*}$ & $0.79 *$ & $\begin{array}{l}\mathbf{0 . 8 2} \\
0.81\end{array}$ & \\
\hline 7. Potency & 4.12 & 3.61 & 7 & 0.66 & -0.09 & $0.62 *$ & $0.74 *$ & $0.74 *$ & $0.86^{*}$ & $*$ & 0.92 \\
\hline
\end{tabular}

Note. Cronbach's alpha coefficients shown along the diagonal. FtFT=face-to-face teams.

$\mathrm{CMT}=$ computer-mediated teams.

$* \mathrm{p}<0.01$

\section{Figure 2}

Results for face-to-face teams.

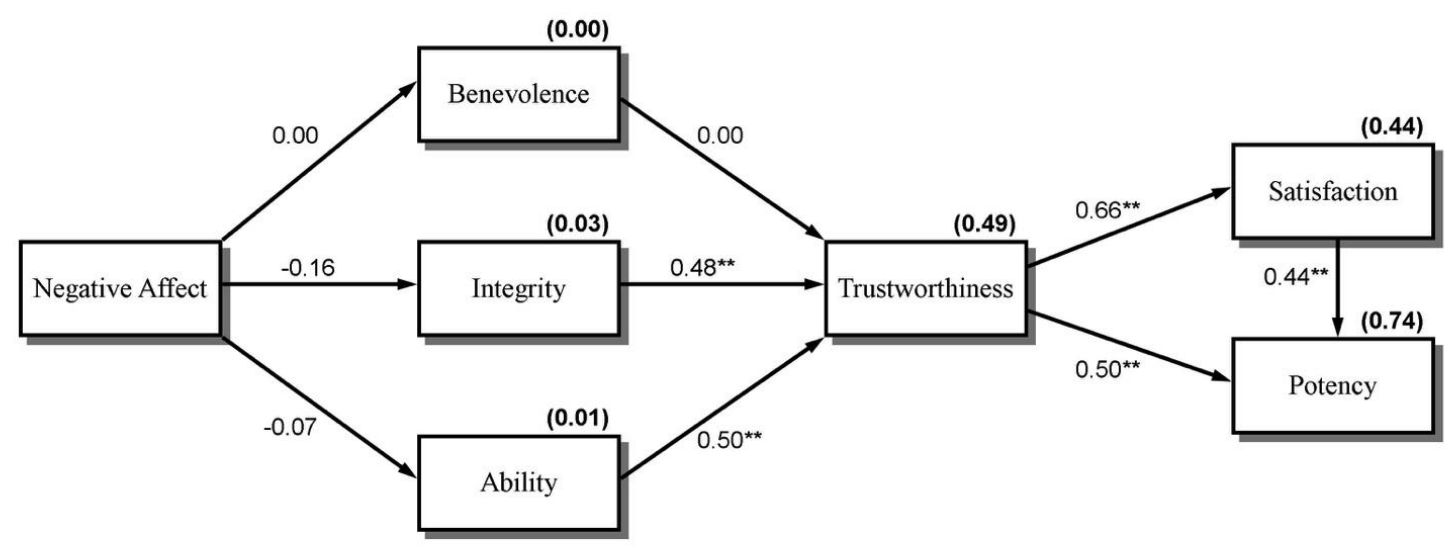

$* * \mathrm{p}<0.01$ 


\section{Figure 3}

Results for computer-mediated teams

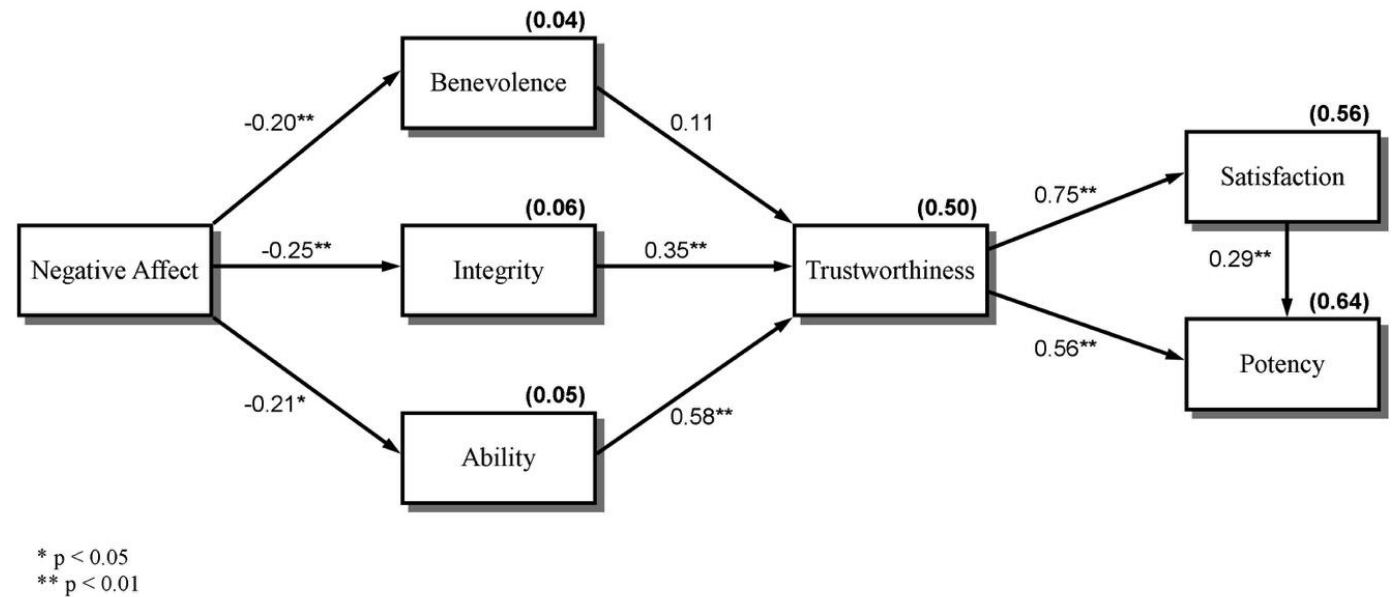

Discussion

Results from this study suggest that gains can be made regarding outcomes by managing the moods of individuals on a team and the collective affect of the group. Consistent with Choi and Cho (2019), benevolence influenced team outcomes. For perceptions of trustworthiness to exist, not only must team members be selected carefully to ensure compatibility, the unique challenges associated with virtual teams is that the system of rewards in which the team operates is part of the social dynamic of that team. The system by which the team members interface is similarly an important consideration given the lens through which team members "see" each other. Cummings and Dennis (2018) found that virtual team members' perceptions are frequently initiated by searches related to other members of the team on social networking sites. Early success of virtual teams thus benefits from making robust information related to fellow team members available to the team.

The team leader plays a role in facilitating trustworthiness among team members. A leaders' positive mood in a group affects team performance positively due to transformational leadership and affirmative group affective tone (Chi et al., 2011). Such leaders and all those who maintain the social dimension of group culture must create a social context in which group members perceive psychological safety, where risks are accepted and encouraged. They do this using tone of voice and willingness to hear ideas (Liu et al., 2015). By focusing on building and maintaining a positive mood, team members perceive a more approachable leader, who encourages promotive and self-advocating voices and rewards members for speaking up and challenging the current situation. A leader's positive mood reduces members' interpretations of feedback received from a member in a negative mood as personal criticism. An example is stating that failure to meet a deadline was partially the leader's fault for not checking in more often, or that it was an unusual occurrence for the member. If communication is misconstrued as positive yet was meant negatively, ostracism and ridicule by the team might result (Liu et al., 2015). People in higher positions, such as managers and instructors, have greater prominence and capability to influence behaviors. The same situation exists in poor relationships between individuals; employees and students learn to assess the mood of a higher-status person before 
using a promotive voice. Cogliser, Gardner, Gavin, and Broberg (2012) found that task- and social-oriented leaders emerge with the characteristics of agreeableness and conscientiousness, which evoke a positive mood and affect team members' behaviors.

When working in CMTs, it is especially important for leaders to reduce stressors. Strategies for dealing with stressors should assist with regulating emotions and thereby preempt disturbances that might result from negative moods and emotions in a team (Vranjes, Baillien, Vandebosch, Erreygers, \& DeWitte, 2017). Since positive moods create positive outcomes and negative moods create negative ones, looking beyond mood and considering resulting behaviors is paramount. Haines (2014) argues that managers of CMTs should create clear team goals, insist on communication between all members, and reiterate that current behaviors might affect future working relationships with team members.

\section{Future Research}

More research on the topic of mood and its effects on teams, particularly CMTs, is needed. Van Kleef, Heerdink, and Homan (2017) suggest that the traditional belief that emotions are detrimental to teams by clouding judgment, causing poorly rationalized and impulsive decisions, is outdated. Van Kleef, De Dreu, and Manstead (2010) found that lowering barriers to emotional displays creates a positive atmosphere and team cohesion. The authors cite the potential of positive emotional contagion and its influence on outcomes, as Schwarz and Clore (1983) identified, arguing that the affect infusion model (Forgas, 1995) evidences that emotions influence information-processing and decision-making schema. Knobloch-Westerwick (2006) suggest that mood management theory can be used to enhance positive moods in group members, altering an individual's information processing and perceptual processes fundamentally. The intricacies of emotions and moods means that social interactions and group functioning research using emotions, as social information theory suggests, is warranted in future studies of virtual and FtF team dynamics. Davis, Kirby, and Curtis (2007) found that mood influences behaviors regarding not only goal-oriented tasks, but in many social interactions, including conflict strategies. Emotions fulfill social functions and aid groups when addressing problems inherent to working with all types of groups. Future research should integrate theories that suggest that emotions and moods link to challenges that teams experience (van Kleef et al., 2017).

Another potential topic for research on moods as antecedents to $\mathrm{FtF}$ and computermediated team outcomes is whether negative and aggressive moods represent stressors at work, and the influence those stressors have on outcomes such as team member cyberbullying in CMTs. Vranjes et al. (2017) argue that confronting work stressors creates negative emotions and moods, which can manifest into cyberbullying. Emotion regulation strategies, such as reappraisal, which means changing how one thinks about a situation or stressor, is useful to countering incivility at work (Vranjes et al., 2017).

Interpersonal emotion regulation (Niven, 2017) is a goal-directed, resource-intensive process that has the potential to affect team members positively by increasing compassion and instrumentality. Emotional regulation is another potential research topic regarding understanding the similarities and differences between $\mathrm{FtF}$ and computer-mediated teams. Emotional regulation 
has long-term implications, such as influencing long-term individual behaviors positively and creating better health outcomes for individuals. Interpersonal emotion regulation means that relationship formation and development are more positive, which allow co-regulation over time. Such regulation is dynamic, creating opportunities for interactions to serve multiple purposes. One topic that should be addressed is use of video-cued recall, during which interactions are video recorded and then replayed numerous times for participants to review interactions retrospectively to identify behaviors that affect goals and emotions (Niven, 2017). Another topic is state-space grids, with which an individual's emotions or states are diagrammed to identify dynamic changes during interactions over time (Niven, 2017).

\section{Limitations}

Participants consisted of students from one university in a single management program. A more diverse sample would provide broader insights into whether the model tested in this paper can be generalized to all students in multiple programs of study. The constructs assessed in this study were conceptualized, measured, and tested only at the individual level; group effects were ignored. Collection of constructs did not mitigate the possibility of single-source bias; both exogenous and endogenous variables were collected from a single source using a single instrument. Future research should consider multi-level theories and use multiple methods to strengthen results and applicability to both research and practice.

\section{References}

Aristotle. (1877). The rhetoric of Aristotle with an commentary by the late Edward Meredith Cope. J. E. Sandys (Ed.). Cambridge, UK: Cambridge University Press.

Barsade, S. G. (2015). Group affect. Annual Review of Organizational Psychology and Organizational Behavior, 2, 21-46.

Barsade, S. G., \& Gibson, D. E. (2000). Group affect: Its influence on individual and group outcomes. Current Directions in Psychological Science, 21(2): 119-123.

Breuer, C., Huffmeier, J., \& Hertel, G. (2016). Does trust matter more in virtual teams? A metaanalysis of trust and team effectiveness considering virtuality and documentation as moderators. Journal of Applied Psychology, 101(8), 1151-1177.

Chesin, A., Rafaeli, A., \& Bos, N. (2011). Anger and happiness in virtual teams: Emotional influences of text and behavior on others' affect in the absence of non-verbal cues. Organizational Behavior and Human Decision Processes 116, 2-16.

Chi, N., Chung, Y., \& Tsai, W. (2011). How do happy leaders enhance team success? The mediating roles of transformational leadership, group affective tone, and team processes. Journal of Applied Social Psychology, 41(6), 1421-1454.

Choi, O., \& Cho, E. (2019). The mechanism of trust affecting collaboration in virtual teams and the moderating roles of the culture of autonomy and task complexity. Computers in Human Behavior, 91, 305-315.

Chua, R. Y. J., Ingram, P., \& Morris, M. W. (2008). From the Head and the Heart: Locating Cognition- and Affect-From the Head and the Heart: Locating Cognition- and AffectBased Trust in Managers' Professional Networks Based Trust in Managers' Professional Networks. Academy of Management 51(3), 436-452 
Cogliser, C. C., Gardner, W. L., Gavin, M. B., \& Broberg, J. C. (2012). Big Five personality factors and leader emergence in virtual teams: Relationships with team trustworthiness, member performance contributions, and team performance. Group \& Organization Management, 37(6), 752-784.

Connelly, C. E., \& Turel, O. (2016). Effects of team emotional authenticity on virtual team performance. Frontiers in Psychology, 7, 1-13.

Costa, A. C., Fulmer, C. A., \& Anderson, N. R. (2018). Trust in work teams: An integrative review, multilevel model, and future directions. Journal of Organizational Behavior, 39, 169-184.

Cropanzano, R., \& Mitchell, M. S. (2005). Social exchange theory: An interdisciplinary review. Journal of Management, 31, 874-900.

Cummings, J., \& Dennis, A. R. (2018). Virtual impressions matter: The effect of enterprise social networking sites on impression formation in virtual teams. MIS Quarterly, 42(3), 697-717.

Davis, M. A., Kirby, S. L., \& Curtis, M. B. (2007). The influence of affect on goal choice and task performance. Journal of Applied Social Psychology, 37, 14-42.

Desilver, D., \& Pew Research Center. (2020, March 21). Working from home was a luxury for the relatively affluent before coronavirus - not any more. Retrieved 23 April 2020 from https://www.weforum.org/agenda/2020/03/working-from-home-coronavirus-workersfuture-of-work/

Forgas, J. P. (1995). Mood and judgment: The affect infusion model (AIM). Psychological Bulletin, 117(1), 39-66.

Fowler, J. H., \& Christakis, N. A. (2008). Dynamic spread of happiness in a large social network: longitudinal analysis over 20 years in the Framingham Heart Study. British Medical Journal, 337(a2338), 1-9.

Fuller, C. M., Marett, K., \& Twitchell, D. P. (2012). An examination of deception in virtual teams: Effects of deception on task performance, mutuality, and trust. IEEE Transactions on Professional Communication, 55(1), 20-35.

Furst S. A., Reeves, M., Rosen, B., \& Blackburn, R. S. (2004). Managing the life cycle of virtual teams. Academy of Management Executive, 18(2), 6-20.

Gardner, H. K., \& Matviak, I. (2020, April 16). Coronavirus could force teams to work remotely. Retrieved 1 May 2020 from https://hbr.org/2020/03/coronavirus-could-force-teams-towork-remotely

Guillory, J., Spiegel, J., Drislane, M., Weiss, B., Donner, W., \& Hancock, J. T. (2011). Upset now?: Emotion contagion in distributed groups. In Proceedings of the International Conference on Human Factors in Computing Systems, 745-748.

Guzzo, R. A., Yost, P. R., Campbell, R. J., \& Shea, G. P. (1993). Potency in groups: Articulating a construct. British Journal of Social Psychology, 32, 87-106.

Haines, R. (2014). Group development in virtual teams: An experimental reexamination. Computers in Human Behavior, 39, 213-222.

Hempel, P. S., Zhang, Z.-X., \& Tjosvold, D. (2009). Conflict management between and within teams for trusting relationships and performance in China. Journal of Organizational Behavior, 30(1), 41-65. https://doi.org/10.1002/job.540

Herbst, J. (2020, March 26). We're in the midst of a massive work-from-home experiment. What if it works? Retrieved 1 May 2020, from https://www.fastcompany.com/90481356/werein-the-midst-of-a-massive-work-from-home-experiment-what-if-it-works 
Jarvenpaa, S. L., Knoll, K., \& Leidner, D. E. (1998). Is anybody out there? Antecedents of trust in global virtual teams. Journal of Management Information Systems, 14(4), 29-64.

Jung, D. I., \& Sosik, J. J. (2003). Group potency and collective efficacy. Examining their predictive validity, level of analysis, and effects of performance feedback on future group performance. Group \& Organization Management, 28(3), 366-391.

Keyton, J. (1991). Evaluating individual group member satisfaction as a situational variable. Small Group Research, 22(2), 200-219.

Knobloch-Westerwick, S. (2006). Mood management: Theory, evidence, and advancements. In J. Bryant \& P. Vorderer (Eds.), Psychology of entertainment (pp. 239-254). Mahwah, NJ: Lawrence Erlbaum Associates.

Kramer, A. D. I., Guillory, J. E., \& Hancock, J. T. (2014). Experimental evidence of massivescale emotional contagion through social networks. In Proceedings of the National Academy of Sciences, 1-3.

Kuo, E. W., \& Thompson, L. F. (2014). The influence of disposition and social ties on trust in new virtual teammates. Computers in Human Behavior, 37, 41-48.

Lapidot-Lefler, N., \& Barak, A. (2012). Effects of anonymity, invisibility, and lack of eyecontact on toxic online disinhibition. Computers in Human Behavior, 28, 434-443.

Lawler, E. J. (2001). An affect theory of social exchange. American Journal of Sociology, 107(2), 321-352.

Likoebe, M. M., \& Agarwal, R. (2004). Managing team interpersonal processes through technology: A task-technology fit perspective. Journal of Applied Psychology, 89(6), 975-990.

Liu, W., Tangirala, S., Lam, W., Chen, Z., Jia, R. T., \& Huang, X. (2015). How and when peers' positive mood influences employees' voice. Journal of Applied Psychology, 100(3), 976989.

Lowry, P. B., Schuetzler, R. M., Giboney, J. S., \& Gregory, T. A. (2015). Is trust always better than distrust? The potential value of distrust in newer virtual teams engaged in shortterm decision-making. Group Decision and Negotiation, 24(4), 723-752.

Mayer, R. C., \& Davis, J. H. (1995). An integrative mode of organizational trust. Academy of Management Review, 20(3), 709-734.

Niven, K. (2017). The four key characteristics of interpersonal emotion regulation. Current Opinion in Psychology, 17, 89-93.

Paul, D. L., \& McDaniel Jr., R. R. (2004). A field study of the effect of interpersonal trust on virtual collaborative relationship performance. MIS Quarterly, 28(2), 183-227.

Pearce, J. L., Sommer, S. M., Morris, A., \& Frideger, M. (1992). A configurational approach to interpersonal relations: Profiles of workplace social relations and task interdependence. Unpublished manuscript, Graduate School of Management, University of California, Irvine.

Pfaff, M. S. (2009). Effects of mood and stress on group communication and performance in a simulated task environment (Doctoral dissertation). Available from Dissertation Abstracts International (Section B: The Sciences and Engineering, 69[8-B], 5085).

Pfaff, M. S. (2012). Negative affect reduces team awareness: The effects of mood and stress on computer-mediated team communication. Human Factors. Special Issue: Methods for the Analysis of Communication, 560-571.

Pfaff, M. S., \& McNeese, M. D. (2010). Effects of mood and stress on distributed team cognition. Theoretical Issues in Ergonomics Science, 11(4), 321-339. 
Piccoli, G., \& Ives, B. (2003). Trust and the unintended effects of behavior control in virtual teams. MIS Quarterly, 27(3), 365-395.

Potter, R. E., \& Balthazard, P. A. (2002). Virtual teams interaction styles: Assessment and effects. International Journal of Human-Computer Studies, 56(4), 423-444.

Robert Jr, L. P., \& You, S. (2018). Are you satisfied yet? Shared leadership, individual trust, autonomy, and satisfaction in virtual teams. Journal of the Association for Information Science and Technology, 69(4), 503-513.

Ruiller, C., Van Der Heijden, B., Chedotel, F., \& Dumas, M. (2019). You have got a friend. Team Performance Management, 25(1/2), 2-29.

Schoorman, F. D., Mayer, R. C., \& Davis, J. H. (2016). Empowerment in veterinary clinics: The role of trust in delegation. Journal of Trust Research, 6(1), 76-90.

Schwarz, N., \& Clore, G. L. (1983). Mood, misattribution, and judgments of well-being: Informative and directive functions of affective states. Journal of Personality and Social Psychology, 45(3), 513-523.

Totterdell, P., Kellett, S., Teuchmann, K., \& Briner, R. B. (1998). Evidence of mood linkage in work groups. Journal of Personality and Social Psychology, 74(6), 1504-1515.

Tseng, H., \& Ku, H. (2011). The relationships between trust, performance, satisfaction, and development progressions among virtual teams. Quarterly Review of Distance Education, 12(2), 81-94.

van Kleef, G. A., De Dreu, C. K. W., \& Manstead, A. S. R. (2010). An interpersonal approach to emotion in social decision making: The emotions as social information model. In M. P. Zanna (Ed.), Advances in experimental social psychology Vol. 42 (pp. 45-96), Burlington, VT: Academic Press.

van Kleef, G. A., Heerdink, M. W., \& Homan, A. C. (2017). Emotional influence in groups: The dynamic nexus of affect, cognition, and behavior. Current Opinion in Psychology, 17, $156-161$.

Volmer, J. (2012). Catching leaders' mood: Contagion effects in teams. Administrative Sciences, 2, 203-220.

Vranjes, I., Baillien, E., Vandebosch, H., Erreygers, S., \& DeWitte, H. (2017). The dark side of working online: Towards a definition and an Emotion Reaction model of workplace cyberbullying. Computers in Human Behavior, 69, 324-334.

Watson, D., Clark, L. A., \& Tellegen, A. (1988). Development and validation of brief measures of positive and negative affect: The PANAS Scales. Journal of Personality and Social Psychology, 54(6), 1063-1070.

Yilmaz, G. (2016). What you do and how you speak matter: Behavioral and linguistic determinants of performance in virtual teams. Journal of Language and Social Psychology, 35(1), 76-97. 